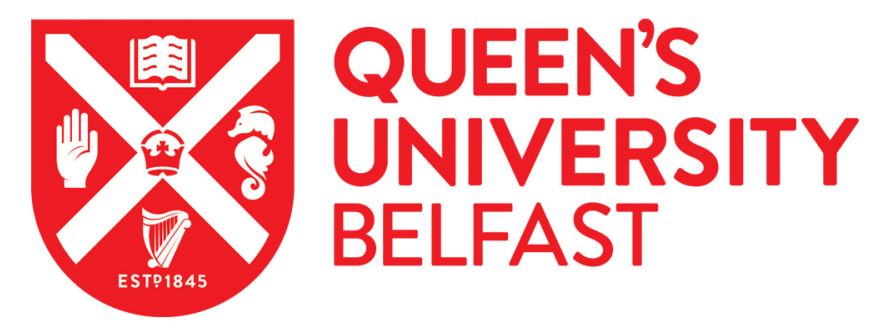

\title{
The role of hospice in the transition from hospital to home for technology-dependent children-A qualitative study
}

Price, J., McCloskey, S., \& Brazil, K. (2018). The role of hospice in the transition from hospital to home for technology-dependent children-A qualitative study. Journal of Clinical Nursing, 27(1-2), 396-406.

https://doi.org/10.1111/jocn.13941

Published in:

Journal of Clinical Nursing

Document Version:

Peer reviewed version

Queen's University Belfast - Research Portal:

Link to publication record in Queen's University Belfast Research Portal

Publisher rights

() 2017 John Wiley \& Sons Ltd.

This work is made available online in accordance with the publisher's policies. Please refer to any applicable terms of use of the publisher.

\section{General rights}

Copyright for the publications made accessible via the Queen's University Belfast Research Portal is retained by the author(s) and / or other copyright owners and it is a condition of accessing these publications that users recognise and abide by the legal requirements associated with these rights.

Take down policy

The Research Portal is Queen's institutional repository that provides access to Queen's research output. Every effort has been made to ensure that content in the Research Portal does not infringe any person's rights, or applicable UK laws. If you discover content in the Research Portal that you believe breaches copyright or violates any law, please contact openaccess@qub.ac.uk. 


\title{
The role of hospice in the transition from hospital to home for technology dependent children - a qualitative study.
}

\begin{abstract}
Aim: This paper reports on parent and professional perspectives of step down care in assisting the transition from hospital to home, within one children's hospice in a constituent country of the United Kingdom.

Background: In recent years increasing numbers of children dependent on long term assisted ventilation have been noted. Meeting the complex physical, emotional and social needs of the child and family is challenging. Many of these children spend extended periods in hospital even when medically stable.
\end{abstract}

Design: This was a qualitative study using an inductive, semantic analytic approach within a realist epistemology.

Methods: Data collection was carried out in 2013. Interviews took place with parents $(n=5)$ and focus groups with professionals $(n=26)$ who had experience of step down care

Results/Findings: Multiple benefits of step down in the hospice were clear. Both sets of accounts suggested that for children and families life was 'on hold' in hospital. Hospice was considered a home-like environment where the child and family could 'live again'. Parents reflected that, in hospice they were 'living, not existing' while professionals highlighted hospice as nurturing and empowering the whole family, promoting the child's development while safely meeting their clinical needs.

Conclusion and implications for practice: The study highlights a number of crucial benefits to the child and family both in the immediate and longer terms. The collective perspectives therefore endorse hospice as a potential viable choice for these children and their families during the always difficult, usually protracted transition from hospital to home.

\section{'What does this paper contribute to the wider global clinical community?'}

- The study reports for the first time the benefits of 'step down' care in the transition process for children between hospital and home, as perceived by parents, professionals and managers.

- The findings indicate that hospices offer a safe environment with a better quality of life for children with technological dependency (when they are medically stable) and families compared to the hospital environment.

- The findings highlight the contribution that children's hospices may make as one initiative in this challenging and multi-faceted arena of protracted discharge from hospital for children who are technological dependent. 


\section{Introduction}

Since the 1950's, reports have consistently recognised that sick children should be cared for, wherever possible outside hospital (Platt, 1959; House of Commons Select Committee Report, 1997; National Service Framework for Children, Young People and Maternity Services, (Department of Health, 2004). However, despite policy directives, international evidence reports that the discharge process for children with complex health needs remains protracted (Hewitt-Taylor, 2011; Davies and Carter, 2013; Brenner et al., 2015) stretching, for some, over many months or years (Halley, 2012). This has major implications for the child and their family, and for the professionals and organisations supporting them (Wang and Burnard, 2004;Tearl et al, 2006). Exploring ways of decreasing the negative impact on all those involved, therefore is an important clinical issue for nurses and professionals across countries.

\section{Background}

Globally, the number of technology dependent children has increased over the past decade (Tearl et al., 2006, Wallis et al., 2011; Amin et al. 2014). A widely used definition emanating from North America identifies the specific characteristics of this group as children who rely

on: “...a medical device to compensate for the loss of a vital bodily function and substantial and ongoing nursing care to avert death or further disability" (Wagner et al. 1987, p.3). A specific example are highly dependent children reliant on mechanical ventilator support being cared for at home, with the number in the UK rising from 93 in 1998 to 844 in 2008-an eight fold increase over a ten year period (Wallis et al. 2011).Care in the community has become a viable and important option for these children, where home provides a more normal and nurturing family environment, improved quality of life, fewer 
infections, more social interactions and a positive impact on child development (Murphy, 2001).

Caring for technology dependent children affects all aspects of family life. They are reliant on 24 hour care, provided by a skilled team of carers (parents and professionals). Constant vigilance is crucial as the children are vulnerable to sudden catastrophic changes. These factors place considerable demands onto parents, who find themselves, not through choice, adopting the additional roles of competent, confident carers, advocates, case managers and guards (Kirk et al., 2005; Carnevale et al. 2006; Murphy et al. 2006; Whiting 2014; Woodgate et al. 2015). The psychological impact also requires consideration, with families reporting feeling overwhelmed, ill prepared and isolated when learning to take care of their child at home (Heaton et al.,2003; Margolan et al., 2004). Additionally, support packages need commissioning and the home often altered to promote safe care (Brenner et al., 2015). These factors alongside complicated discharge processes often result in children remaining in hospital beyond the point where they are considered medically stable (Carter et al., 2016). In fact one study reported the average time spent in hospital for children reliant on tracheostomy assisted ventilation awaiting discharge was 9.6 months (Smith \& Hillard, 2010). Whilst families and professionals are committed to the position that the best place to care for these children is at home where possible, achieving this is challenging (Kirk \& Glendinning, 2004; Tearl et al., 2006). As many of these children are likely to die before adulthood, the imperative to improve the transition to home is even more pressing.

Children's hospices originated in the United Kingdom in the 1980s with the opening of the world's first children's hospice: Helen House in Oxford. Growth in the numbers of hospices and services provided have ensued over the years, with other countries such 
as Canada and Australia adopting the UK model of children's hospice care for children with life limiting conditions and their families. Care may be provided in community settings or in bespoke facilities. Hospices commonly provide specialist short breaks, end of life care and bereavement support offered through a model of child and family centred care, delivered by a multi-disciplinary team (Together for Short Lives, 2016). In recent years, a number of children's hospices have augmented their services by providing step down care to technology dependent children experiencing a protracted discharge from hospital to home. In the context of this study, step down care was:

" a term used to reflect the transition from a highly medicalised hospital environment with prompt access to a multi-professional team of doctors, nurses and allied health professionals, to the more home like hospice environment where care is delivered by a nurse led team in a closer manner to the way care will be delivered at home." (McCloskey \& Price, 2014, p. 6)

In 2013, 24 children's hospices in the UK out of the 44 contacted responded to a postal survey, with 15 hospices reporting they currently or previously provided step down care (McCloskey and Price, 2014). Referrals for step down care may arise for various reasons, such as to provide an interim location to enable parents develop the necessary competencies to care for their child, or to improve the child's environment of care while care packages are finalised or housing adaptations completed.

Whilst Cockett's (2012) literature review suggested that children with technology dependency and their families have been widely researched, no substantive research exists regarding the potential role of children's hospice in the transition from hospital to home for this group of children. Since this is a relatively new, small and developing area of care the lack of such research is not surprising. This study sought to address this gap. 
This paper is taken from a larger study which aimed to evaluate the impact, outcome and potential added value that step down care provided by a children's hospice offered to children who are technology dependent on ventilator support, their families, service providers and commissioners when provided by a children's hospice. The focus here is to report one strand of the study's activity- and aims to answer the question 'What are parent and professional perspectives of hospice step down care within a constituent country of the UK?'

\section{METHODS}

\section{Design}

As this study sought to explore 'experiences of availing of step down care in a children's hospice from the perspective of parents' and professionals, the use of a qualitative methodology was considered appropriate (Patton 1990). Data were collected through interviews and focus groups and analysed through thematic analysis. The goal of thematic analysis is to identify, analyse, interpret and report patterns and meaning within the data (Braun and Clarke, 2006). Although some researchers view this method as a technique embedded in specific qualitative methodological traditions such as grounded theory or content analysis (Ryan and Bernard, 2000), others argue that thematic analysis is a valid method in its own right (Braun and Clarke, 2006 p.78). Thus an inductive, semantic analytic approach within a realist epistemology was adopted to gain insight into the meanings individuals make in the context of their reality. 


\section{Ethical Considerations}

Ethical approval was sought and granted through ORECNI (12/NI/0186) and was presented to and approved by the Research Governance Committees in the relevant hospice and the respective Trusts. Given the sensitivity of the subject under investigation and specific vulnerability of participants (ie bereaved parents) and professionals working with these life threatened children, specific ethical considerations had to be taken into account (Bahn and Weatherill, 2013). To that end, recommendations developed by Dyregov (2004) were used to guide the design of the study and included how an initial approach was made to parents, the interview setting and process, as well as the support during data collection and also as a follow-up.

\section{Sampling and Recruitment}

\section{Parents}

Parents whose children had received step down care in one specified children's hospice were invited to take part in the study. A total of 2 children and 2 young people had availed of step down care in that children's hospice. This added an additional dimension as the young people were at the point of transitioning from children's services, and their discharge to home required the engagement of adult services less familiar with providing care to young people with the most complex of needs. Invitations were extended to all four families (the total population) who had experiences of step down care. Initial contact was made by a professional well known to the family, who, where parents were in agreement, provided a pack from the researcher including a cover letter, information 
sheet, return forms and a stamped addressed envelope. As in other studies (Hynson et al. 2006; Akard et al. 2014), parents bereaved in the last six months were excluded from the study as it was viewed that this was a particularly difficult time for families. One child died during recruitment and thus the family was outside the set criteria. Three families therefore participated ( 2 heterosexual couples (interviewed together) and one single mother) (table 1).

\section{Professionals}

A purposive sample of professionals was recruited on the basis that they had experience of working with any of the four children and their families during the transition from hospital towards home. Recruitment of professionals took place from the tertiary children's hospital, community services from 2 health and social care trusts (geographical areas) and 1 children's hospice. Principal Investigators in each site were requested to use their professional judgement to distribute participation packs to colleagues who had contributed to these children and young people's care.

\section{Data Collection}

\section{Parents}

Whilst telephone interviews have particular merits (King and Horrocks, 2010) and were considered for this study, it was felt that given the sensitivity of the subject under investigation interviews should be carried out in person. Thus, data collection from parents took the form of a face to face interview. Interviews are, viewed as appropriate where little is already known about a phenomenon and where comprehensive insights are needed from individual participants (Gill et al., 2008). In keeping with the principles of interpretive research, in-depth interviews, guided by a topic guide, were employed on the grounds that this type of approach enabled exploration of issues inherent in the study objectives, those suggested in the 
literature as well as those introduced spontaneously by parents (Johnson, 2002; King and Horrocks, 2010). Thus these characteristics made interviews suitable for this study which had pre-designated areas of interest but remained open to the potential relevance of other issues. Interviews with 2 parent pairs and 1 single parent were carried out in a place of parent choosing ( 2 being in the family home and one in a room within hospice). Clear direction as to whether or not parents should be interviewed separately or together is relatively absent in the literature with papers reporting ambivalent positions expressing both advantages and disadvantages (Arskey, 1996; Arskey \& Knight, 1999; Valentine, 1999). Given that the study was examining family experiences a decision was made to interview together. An added benefit of joint interviews, is their potential to enhance the comprehensiveness of data, as interviewees could and indeed did fill in gaps in the memory of the other. Interviews were recorded with permission using a digi-recorder and were transcribed verbatim by an experienced typist who had signed a confidentiality form. The researcher did not take notes during the interview, in order that they could be respectful in giving the participant their full attention. Summary notes were taken immediately after the interview by the researcher.

Semi-structured interview topic guides directed the discussions. To increase rigor, the parent topic guide was discussed with another hospice parent outside the study criteria. This asked parents to tell their story about their child, their care needs, their hospitalisation and their discharge from hospital.

\section{Professionals}

Data from professionals was collected through five focus groups also directed by a topic guide, with 26 of the 62 professionals invited, taking part (table 2). Each group 
was heterogeneous in terms of professional representation to encourage a full exploration of different experiences of step down care (Goodman and Evans, 2010). Focus groups were selected as the preferred method as the collective discussion encourages participants to build upon previous responses and the exchange of ideas often generates richer data than individual interviews (Kruger \& Casey, 2015). The groups were formed on an organisation specific basis to maximise the benefit of bringing together participants with shared, similar characteristicsand experiences (Polit and Beck, 2014). In this case, participants had experience of step down care relating to the same child and family. Invitation letters had been sent to all potential participants along with a participant information sheet (PIS) opportunities were given for asking questions before they decided to attend one of the group sessions. On the day informed consent was taken from those who decided to participate after they had been given a further chance to ask questions. The groups were audio recorded with participant permission.

All aspects of data collection were undertaken by the same experienced children's palliative care nurse/qualitative researcher (JP) who was independent from the hospice, thus improving the rigor of the data collection process. Data saturation occurred during data collection since no new ideas emerged from subsequent interviews.

\section{Data Analysis}

The 6 stage approach to thematic analysis (Braun \& Clarke, 2006) was utilised as a nonprescriptive guideline. Since thematic analysis is a comparative process (Boyatzis, 1998), data were gathered and compared, within and across accounts, to classify patterns of 'themes' that recurred across the entire dataset (Ryan and Bernard, 2003). 
Systematic processes utilised to ensure rigour in all aspects of this study were woven throughout the research process some aspects of ensuring rigor have been already highlighted in terms of study design and data collection. In addition it is important to highlight that rigor within the analysis, was promoted in a number of ways. Firstly analysis took place through an iterative process involving the members of the research team (JP and $\mathrm{SMcC}$ ), whereby the transcripts were independently analysed and the team came together to discuss future direction of the analysis and to seek consensus on the findings. Secondly. the centrality of techniques identified by Silverman (2000) as a core means of ensuring credible research were also adopted within the analysis stage of this study those being analytical induction and the comprehensive treatment of data (involving the two techniques of constant comparative analysis and deviant case analysis).

\section{RESULTS}

\section{Parent results}

Each parent narrative reflected their individualised experiences and whilst variation was noted in the parents age and the nature of their child's condition, commonalities arose through the analysis process. Four main distinct, but interconnected themes were evident centring round a chronology: 'Away from home', 'Wanting Home', 'Feels like home', and 'Being at home'. Each theme consisted of a number of subthemes (table 3). Similarly, commonalities of professional experiences were noted, giving rise to 5 core themes and associated sub themes which helped to explain experiences of those caring for the children and families who accessed step down care (see table 4).Here we firstly present findings from parents followed by themes from focus groups with professionals. The discussion section brings both perspectives together which enables a more robust set for recommendations to enhance clinical practice. 


\section{Away from home}

Parents initially recounted a time where they clearly recognised that their child needed to be hospitalised and 'away from home'. Such realisation may have been at birth or when their child experienced a catastrophic event for example a respiratory arrest. Whilst parents recognised the need to be 'away from home' and to be in hospital, they had hoped that hospital could 'fix' their child. However, parents recalled a point when parents realised that no further medical improvement in their child's condition was likely, and their child was considered medically stable. Parents then perceived hospitals as unsuitable, and a place where the child's safety was potentially compromised (ie infection risk). They also voiced frustration at the lack of stimulation for their child and feelings that their child was 'existing not living' permeated their accounts. This was heightened further when young people were cared for in adult wards.

Being 'away from home' and the associated protracted hospitalisation resulted in sustained disruption of family life. The family unit was fragmented with parents feeling that they were less available for siblings. This generated feelings of guilt:

‘...because the kids still had to go to school and... life still had to kind of go on, so ... I would have went down first thing in the morning. Yeah, I would have got the kids out to school, drove down first thing in the morning, and ((dad)) had stayed all night with ((child))'.

\section{Wanting home}

Combined worries and anxieties emanating from being in hospital and the impact on child/family life contributed to parents' strong feelings of 'wanting home'. Such a determined desire appeared driven by parental determination that home could provide some sort of normality for the child and family. In addition, the view that home provided, as parents saw it, a much 'safer' environment for the child, further endorsed parents wish of 'wanting home'. Despite such strength of conviction, that home was the right 
environment for their child and family, parents were anxious about how they would manage their child's complex technological needs there.

Moreover, parents' accounts highlighted that, in navigating towards home, they encountered multiple, complex obstacles, such as lengthy planning meetings, inconsistent communication, arguments about costs and challenges securing and training carers. These were outside of their control, leaving parents frustrated:

'So, we did meet with her boss and we tried to put it quite strongly that, eh, we need this package in order to get him home. Whilst she didn't say, no, well, we can't provide it, ... this rationale was presented of "I don't have people trained" and it's hard to get a number of people to give you 24-hour care and this will take a long time.'

Through the ensuing struggles, 'another option'-transition to the children's hospice became apparent. Initially the name 'hospice' conjured up negative feelings for some parents who associated hospice exclusively with death. A visit to hospice banished parental misconceptions and subsequently the option brought hope to parents, providing them a way out of the medicalised environment that they now felt was detrimentally impacting on their child.

Feels like home

The child's transfer from hospital to hospice was a turning point in all parent's stories. Hospice provided clinical security for parents in an environment that 'feels like home' and thus this became the next analytically defined stage.

Parents clearly articulated their belief that hospice initiated an almost immediate, somewhat miraculous change in their child which they attributed to the support they and their child received and to the environment. Of note were small, thoughtful acts of kindness which were easier to provide in the hospice environment, where staff had more time to tailor care to the child and family's needs and wishes. Parents suggested that 
such individualised care was more difficult to deliver in hospital and something they suspected became a source of frustration for professionals working in acute settings.

Parents reported multiple positive experiences in relation to the child's needs regarding their physical, emotional, social and developmental care. Additionally, hospice was able to provide time and space to support the whole family.

'It is definitely far homelier...you're sitting drinking coffee with the girls and...everybody gets on, do you know? ... they're too busy in the hospital.... they've more time in hospice.'

Parents recognised that by not having to take care of daily tasks like preparing meals, hospice provided them with precious family time and enabled them to develop the knowledge, skill and confidence to parent their child in a different way. Parents who talked as if they were on the periphery of care in the hospital now felt they were central to their child's care once more, especially when their considerable expertise was acknowledged:

'Yeah, it really gave us the confidence to know that... what they always said was, as parents, nobody can look after your child as well as you. Nobody can do it. They'll never be able to do it. They might have all the exams and whatever, but we're... we know him. You know, we can look at his face and say he's going to go off. You know, we knew it. Being told that...you know that, you're his mum, you know that. Yes, and for them to build that confidence up in you, and for the kids, for our kids, to go "You can help your brother," you know, you can be there, you can do this, and build that confidence in them, was fantastic.'

In contrast to hospital, hospice was viewed as creating a homelike family environment where 'living, not existing' happened.

\section{Being at home}


Whilst 'feels like home' prevailed in parent stories, awareness that hospice was not a long term solution became apparent. The ultimate goal and wish 'being at home' thus resurfaced and replaced 'feels like home' in parent narratives.

Securing care packages to support the child at home remained a protracted process, causing untoward parental stress. Parents often perceived these delays as hampering, or diluting the precious time of 'being at home':

Initially, the reality of 'being at home' and the responsibilities that brought for the family proved daunting. However, such feelings were eased by short spells (half days) at home building up to longer periods, as the child moved towards discharge (for some) over time.

'M: We got him home for half a day with the physio and nurse...that took such organisation. They got in an oxygen machine, oxygen cylinders...

$D$ : They had to organise three extra machines and tubes and...

M: Suction catheters... They came out and made sure that his room was okay and we were able to get granny and granddad up, and his aunt and uncle, and we took him outside onto the decking and we had a party almost. Our daughter did the cooking and...And then...we got him home again and they left us for a few hours'.

Hospice staff were present in the family home during the phased transition, skilfully stepping back as parents gained confidence to care in their own environment. This, parents equated as being 'almost visible, but there'.

Within the discharge process a second transition took place, resulting from the withdrawal of hospice staff and the embedding of community nurses and carers within the child/family's circle of care. Although hospice staff were always available at the end of the phone, a shift in the relationship was experienced when the step down process was completed and the child was at home full time. Severing of the intensive, reciprocal relationship developed between hospice staff and the child was a wrench for all concerned. 
Getting home was a goal unattained for some families as their children died before this process was completed. However, irrespective of the final outcome of the step down process, families recognised the gift of valuable family time step down at hospice had brought them.

\section{Professional results}

Similarly to parents, professionals across groupings identified the protracted nature of the discharge process, which was analytically defined as 'the long road home'.

\section{The long road home}

The complex process experienced by professionals, in their strive to get the child home was exacerbated by the need to assess and address the multiple risks involved, secure funding, employ and train carers, train parents and possibly adapt to the family home. As with parental accounts, professionals too, identified much frustration inherent in the process with professionals adopting fighting terminology to capture their experience.

'It feels like a battle every time you're trying to... send a child home, it's, oh, here we go...'FG 2

Whilst professionals working in both hospital and community settings recognised that hospital was not the best place for a medically stable child, the confounding factors contributing to the pressure to discharge the child appeared different. Hospital staff discussed pressure to free a bed and community staff felt under pressure to accept the child home sooner than they were ready.

'We're under increasing pressure from the hospital side about blocking beds, needing to move, winter's coming in, infections are rife, and it's move, move, 
move. So, we're being propelled and driven along a road at a rate that...the two things are at odds necessarily with each other.' FG3

These factors alongside the complexity of the child's needs led to a process that was both time consuming and frustrating for all concerned. Although the road was long, professionals were determined to get the child home so they could start 'Living again'. Living again

In keeping with parents views that hospice enabled their child to start 'living as appose to existing', professionals unanimously reflected that step down care in the hospice enabled and empowered children and their families to 'live again'. The strength of the conviction in hospice's capacity for 'Living again', seemed propelled by the unswerving belief that the hospital environment by contrast was not only limiting child and family opportunities, but was a risk-ladened environment, where exposure to infection could lead to the child's death.

Professionals perceived that the child's life was on hold in the hospital and they became insititutionalised. Medical needs associated with the child's technology dependency were viewed as the main priority, while their emotional, psychological and developmental needs were not addressed to the same extent.

'One of the other families as well, what they would have said was that, up until their child came here (hospice), they were waiting for him to die in the hospital, what they were doing on a day and daily basis. Here, they learned to... you know, to enjoy him living again. It was the way that they... what they would have talked about, and they were able to enjoy those experiences and able to just allow themselves to enjoy the days that he then had, whereas, in the hospital, they were just waiting for him to go really.'FG1 
In contrast, the hospice model provided an opportunity to address such needs: a view also endorsed by parents. Play and other stimulating activities and experiences, enabled the children to fully 'live again'.

'So... and then they get here (hospice) and the care that we provide meets a whole lot of needs that weren't being met, em, not through...just because it was a different setting.' FG1

The promotion of 'family togetherness' was noted as being largely hampered within the hospital with, for example limited facilities for parents, and when visits from siblings were not permitted. 'Living again' was associated with the presence of 'expert' staff, who could not only make the most of each moment to address the child and family's needs, but could also skilfully support families to gain the necessary confidence and competencies to care for their child.

\section{Learning to care}

'Learning to care', as it arose from the data, involved both professional and parental learning which was considered crucial to the step down process. The highly dependent nature of the child's needs was challenging for the staff across locations, with hospice staff also reflecting anticipatory anxiety prior to the child's transfer. However, core, transferable skills gained through caring for other children with highly complex needs enabled staff members to quickly develop confidence in the child's care. This was understandably more challenging for community staff, and especially nurses trained in the care of adults, who would be responsible for supporting the child or young person at home:

'I think children's nurses are more equipped to deal with the technology-dependent side of things than adult services maybe, albeit that they, you know, have the services in hospital, but maybe things like trachies and NG tubes are...em...something that isn't routinely performed by the district nurse at home 
per se and the patient has to go back to the hospital for, and from that perspective.' FG5

'Learning to care', involved parents regaining lost confidence and developing the clinical skills needed to care for their child. Initially, parents felt overwhelmed by the task, but the supportive and conducive environment enabled their fears to be acknowledged and learning to take place, building upon the programme initiated in the hospital. This approach enabled parents to gradually gain the necessary confidence and competence to be a parent again, albeit to a child with differing and complex needs. Participants highlighted the individualised nature of teaching and the capacity for hospice professionals to take account of the wider context of caring for a child within the home and community settings which extended the scope beyond the competent completion of clinical skills.

'And I think, as well, the Hospice look at the parenting skills, how they are as a parent, not only at how they are as being competent to deliver clinical care, and that's a big difference... but there's more to looking after a child at home than sucking them out, doing their physio, and doing their care. You know, it's about...the decision-making of those parents... and the Hospice staff would be very clued into that side of it, whereas the hospital, it's an acute facility, and they are focused on clinical care and that is their focus there, you know.' FG4

Developing professional partnerships

The pivotal role of developing strong partnerships between hospice and Trust staff in providing step down care was highlighted and thus became the 4th theme. These multiple and multi-faceted partnerships were, viewed by participants as crucial for successful caring.

'We (the community services) had a need, they (hospice) had a means of meeting that need, and, together, we were able to work in conjunction'. FG3

The step down process was more straight forward when the Hospice and Community

Service worked in tandem to agreed, consistent policies: 
'And on the back of that, we have very good professional links with the Hospice, really good, because, when I was talking earlier about risks and risk assessment, they get it, the same as we get it. You know, they know what they're doing, they know what is expected, they know that we would think the same, and they use the same delegation framework, the same processes, as we would, and we want them to use. So, in that respect, that's good. Yeah. They understand the community setting I think much...much better'.FG3

Conversely, staff felt frustrated when difficulties were encountered and services were reluctant to work collaboratively:

'... when we first started exploring this, we just came up against a brick wall... people just kept throwing back resources, resources, resources'. FG2

Careful forward planning and communication was central to successful professional partnerships throughout the discharge pathway and beyond. Staff highlighted the importance of transparency about roles and responsibilities for each party.

'It's the Trust's responsibility and it's the Board's responsibility, and we [Hospice] can support them and we can provide care and we will push the boundaries, but it's not our responsibility. We have a responsibly to contribute towards it but... And it's holding that line with people, em, and we need to do that. If this is going to be...if there's going to be any infrastructure around this, and if this is going to be something that is planned on a regular basis for an identified group of children, there have to be processes around it that are recognised'.FG1

\section{Best place, best care}

Professionals appreciated that the hospice not only competently cared for the child but provided a nurturing environment that facilitated the building of parent confidence as reflected in the final theme-'Best place, Best care'

'Best place for them, where they're going to be able to get the care that they require, but they no longer need to be in any hospital environment' (FG2) 
The restricted availability of access to step down care however was a limitation within the model.

'Well, I, personally speaking, couldn't speak highly enough of the Hospice. ...it's a fantastic place for the families, for a start, and the staff there are second to noneyou know, couldn't speak highly enough of it. The problem is that there's not enough of it.' (FG2)

Professionals talked of the need for a more definite arrangement in the future, which addressed not only the discharge pathway to home, but the provision of on-going support when discharge was achieved.

'The ideal position in relation to this cohort of children would be have... would be to have increased respite facilities, opportunities for step-down, and also opportunities for long-term care if that's required, and if it all could be in an environment, one environment, it would be even better because you'd be building on a skill set that already existed.' (FG3)

Professionals therefore called for a strategic approach to addressing these children and families' needs as such guidance is currently lacking in this jurisdiction.

\section{DISCUSSION}

Analysis of both parent and professional data revealed a strong belief that the hospice had much to offer children and families in terms of step down care. Parents and professionals consistently voiced that hospital was not the place for these technology dependent children once they were medically stable. Such an environment, as parents and professionals saw it, was clearly detrimental to the child's wellbeing, particularly their emotional and physical development. The determined strive for 'normality' (Cockett, 2012) or 'an ordinary life' (Davies \& Carter, 2013) which parents with technology dependent children desperately seek, appears to have been facilitated when step down care was provided in hospice. 
Of particular note was the apparent consensus between parents and professionals that, in hospital, life for these children and families stood still, and that once they moved to hospice they started to 'live again'. It was noted that in hospice, children enjoyed improved quality of life and experienced rapidly enhanced development (Murphy, 2001) in an environment that in many respects mimicked home. Hospice also enabled families to be a family again as reflected by parents in the sub theme 'living as opposed to existing' and professional by the 'living again' theme. Hospice models of care have been highlighted by parents in a study (Kirk and Pritchard, 2011) as providing holistic, family centred support which is tailored to the individual needs of the child and family, ensuring control and active involvement is promoted. Such key components of care and support have been endorsed in our study as being particularly transferrable to technology dependent children and families undergoing transition from hospital to home. The adjustment in the power relationship between parents and clinical staff once transferred away from the medical environment, coupled with the supportive staff skilled in palliative care facilitated parents to be parents, whilst developing the new care competencies their child required. Learning to parent again was a planned and gradual process within the hospice environment, where parents' insights and knowledge of their child were recognised as central to this process. Parents felt valued by hospice staff. They felt they could openly express their concerns about taking on aspects of their child's care. This type of negotiation is central to a family and child centred approach to care (Fereday et al., 2010). The study identified that hospice enabled parents to learn not simply the clinical skills required to meet their child's medical care needs, but also to parent their child. Such an approach to skills and confidence development has been defined as 'phased responsibility' (Brenner et al., 2015). Our study supports that parents taking on the responsibility for their child in a gradual way with the knowledge of nearby expert 
support, negates some of the emotional impact and stress associated with tensions created between caring and parenting (Cockett, 2012).

The pressures and anxieties parents experience are clear from this study and the tensions between the role of parent and carer are apparent where the role of parenting has been transposed due to their child's technological needs. In the past Kirk et al. (2005) suggested that the parents' perceptions of nurses raise questions about whether or not the caregiving of nurses truly addresses the individual needs of the child with technological dependency and their family, and whether the expertise of parents is recognised. This study refutes these findings illuminating the belief of parents and professionals that, in an appropriate context and environment, nurses and other professionals can recognise parental expertise and truly focus on the specific needs of the child and family. Regarding the acceptability of hospice, this study reaffirmed earlier findings which highlighted that the term 'hospice' held negative connotations for parents (Kirk \& Pritchard, 2012). Health and social care professionals were very conscious of this, reflecting how they adopted a gentle approach when suggesting hospice as an alternate location for care. A visit was also shown here as being a potent means in changing parents preconceived ideas and illuminating the potential role hospice could play in their child's care.

\section{Limitations and strengths}

The part of the study reported here collected data from 1 hospice, and the sample of 5 parents was small which could be viewed as limitations. However, it is important to recognise that the concept of step down care in a hospice is new aspect of care and further the study represents the full cohort of eligible parents. A particular strength of this study is its provision of differing perspectives, so that in addition to parent carers, the 
views of professionals contributing to the child's care were also collected, making the findings more robust. Further research though is required to examine how hospices can sustain such services and research into the longer term impact on children and their families, as well as on the practitioners supporting their care is also warranted. This study however serves as an important starting point in giving us invaluable insights and future studies could build on this by including larger samples of parents and professionals from multiple centres/hospices. Additionally, a comparative study including children's hospices internationally and their views and experiences of step down care to address this international problem would be worthwhile.

\section{CONCLUSION AND RELEVANCE TO CLINICAL PRACTICE}

Whilst this study has provided evidence of the benefits of step down care, wider factors need considered if this is to become embedded as a component within the discharge pathway for children who are technology dependent. Firstly, it is likely that this will not be the most appropriate option for all children and where possible processes should be maximised to enable swift discharge from hospital to home.

Secondly, it is not suggested that all children's hospices should extend their service to include step down care. This should be considered at a local level according to local needs and priorities, where capacity exists (for example, through currently un-resourced bed spaces which could be mobilised for step down care). Thirdly, this model was integrated into the model of care delivery on a temporary basis so that the service could be piloted and impact assessed. Therefore, short term approaches are not sustainable since this places pressure on core services and staffing levels. 
Developing step down care as a discrete component within a children's hospice model requires funding, a commissioning plan, set pathways with timescales and contracted arrangements to ensure that discharge home does not stall when a child is transferred to the hospice. Since numbers of children with technological needs are increasing and the policy imperative to get them home remains clear, it is important to examine options for children and families and to look at their experiences as service models develop and expand.

Evidence from this study suggests that step down care in a children's hospice has the potential to be both appropriate and beneficial where considered appropriate in terms of local needs and where capacity exists. It provides an example of how a children's hospice acknowledged a pressing need and innovatively responded to meet this need. This, in itself will not solve the challenges of children and families experiencing prolonged hospitalisation where a wider, strategic approach is required. It must be acknowledged that in this jurisdiction, as in many other areas nationally and internationally, efforts are being made to address these challenges (Health and Social Care Board, 2013). This model may provide one possible component within this strategic approach. In addition this study highlights the wide ranging impact of the child's medical condition on both child and family life and also the complexity of systems that can hinder or facilitate care. Future studies should therefore examine the on-going demands families experience post discharge to identify their needs and to inform the development and delivery of ongoing services to best meet these needs. 
Table 1: Characteristics of children using Hospice and represented by parents and professionals in the study

\begin{tabular}{|llll|}
\hline $\begin{array}{l}\text { Child } \\
\end{array}$ & $\begin{array}{l}\text { Age at } \\
\text { transfer }\end{array}$ & Condifion & $\begin{array}{l}\text { Length of time in } \\
\text { hospital prior to } \\
\text { transier to hospice }\end{array}$ \\
\hline $\mathbf{1}$ & $2+$ years & neuromuscular condition & $2+$ years \\
\hline $\mathbf{2}$ & 18 years & neuromuscular condition & $\begin{array}{l}5 \text { months } \\
\text { (cared for in an adult } \\
\end{array}$ \\
& & ward) \\
\hline $\mathbf{3}$ & 19 years & neuromuscular condition & $\begin{array}{l}3.5 \text { months } \\
\text { (cared for in an adult } \\
\end{array}$ \\
& & ward) \\
\hline
\end{tabular}

\section{Table 2:}

Professional groupings participating in the 5 focus groups

$\begin{array}{ll}\text { Professional group } & \text { Number } \\ \text { Nurses } & 8 \\ \text { Carers (employed) } & 1 \\ \text { Doctor } & 1 \\ \text { Social Worker } & 2 \\ \text { Occupational therapists } & 3 \\ \text { Health care/senior } & 2 \\ \text { healthcare assistants } & \\ \text { Physiotherapists } & 1 \\ \text { Educators } & 2 \\ \text { Managers } & 5 \\ \text { Dieticians } & 1\end{array}$




\section{Table 3: Themes and subthemes from parent narratives}

\begin{tabular}{l|l|}
\hline Theme name & Subthemes \\
\hline Away from & - Need for hospital care \\
home & - Fragmentation of family life \\
Wanting home & - Existing not Living \\
& - Fesire for normality \\
& - Another option \\
Feels like & - Child and family as the focus of \\
home & - care \\
& - Little things are big things \\
& - Learning to parent differently \\
& - A short term fix \\
Being at home & - Overcoming the obstacles \\
& - Precious time, Precious \\
& - memories \\
&
\end{tabular}

Table 4: Themes and subthemes from focus groups with professionals

\begin{tabular}{|c|c|}
\hline Theme name & Subthemes \\
\hline The Long road home & $\begin{array}{l}\text { - A battle every time } \\
\text { - Combating impatience } \\
\text { - Addressing the risk }\end{array}$ \\
\hline Living again & $\begin{array}{l}\text { - } \text { Promoting normality } \\
\text { - Flexibility in caring } \\
\text { - Expert support }\end{array}$ \\
\hline Learning to care & $\begin{array}{l}\text { - } \text { Teaching parents to parent } \\
\text { again } \\
\text { - Supportive environment } \\
\text { - } \quad \begin{array}{l}\text { Professional Competence } \\
\text { building }\end{array} \\
\end{array}$ \\
\hline $\begin{array}{l}\text { Developing Professional } \\
\text { partnerships }\end{array}$ & $\begin{array}{l}\text { - Trust and transparency } \\
\text { - Organisations working in } \\
\text { tandem }\end{array}$ \\
\hline Best place, best care & $\begin{array}{ll}\text { - } & \text { Benefits of the service } \\
\text { - } & \text { Restrictions of present } \\
& \text { service } \\
\text { - } & \text { The future service }\end{array}$ \\
\hline
\end{tabular}




\section{References}

Akard, TF Gilmer, MJ., Miller, MJ ., Steele, AC., Hancock, K Barrera, M.,Gerhardt, CA (2014) Factors affecting recruitment and participation of bereaved parents and siblings in grief research. Progress in Palliative Care, 22, 75-79.

Amin, R; Chaves, A; Syed, F; Moraes, T (2012) Technology-Dependent Children: The Chronically Ventilated Child. Current Pediatric Reviews, 8, 2,pp. 114-130(17).

Arskey, H. (1996) Collecting data through joint interviews. Social Research Update, Issue 15, Department of Sociology, University of Surrey.

Arskey, H. and Knight, P. (1999) Interviewing for Social Scientists. London, Sage Publications.

Bahn, S and Weatherill, P (2013) 'Qualitative social research: a risky business when it comes to collecting 'sensitive' data.' Qualitative Research 13 (3): 19-35

Boyatzis, R. (1998) Qualitative Information: Thematic Analysis and Code Development, Sage Publications.

Braun, V. and Clarke, V. (2006) Using thematic analysis in psychology. Qualitative Research in Psychology, 3, 77-101.

Brenner, M., Larkin, P.J., Hilliard, D,C., Howlin, F and Connolly, M (2015) Parents' perspectives of the transition to home when a child has complex technological health care needs. International Journal of Integrated Care. 15, 3,

Carnevale, F., Alexander, E., Davis, M., Rennick, J.and Trioni, R. (2006) Daily living with distress and enrichment: the moral experience of families with ventilator assisted children at home. Pediatrics, 117(1) e48-E60.

Carter, B., Bray, C ., Sanders, C., Miert , C, Hunt and Moore A (2016) "Knowing the Places of Care": How Nurses Facilitate Transition of Children with Complex Health Care Needs from Hospital to Home. Comprehensive Child and Adolescent Nursing.

Cockett, A (2012) Technology dependence and children: a review of the evidence. ursing children and young people. 24, 1, 32-35.

Data Protection Act 1998. Available at: http://www.legislation.gov.uk/ukpga/1998/29/contents.

Davies, J and Carter, B (2013) Living an ordinary life. Journal of Child Health Care. 17(3) 217-218

Department of Health (2004) National Service Framework for Children, Young People and Maternity Services: children and young people who are ill: standard 615. London: Department of Health.

Dyregov, K. (2004) Bereaved parents experiences of research participation. Social Science and Medicine, 58, 2, 391-400. 
Fereday, J., Oster, C. and Darbyshire, P., (2010) Partnership in practice: what parents of a disabled child want from a generic health professional in Australia. Health \& social care in the community, 18(6), pp.624-632.

Gill, P., Stewart, K., Treasure, E and Chadwick, B (2008) Methods of data collection in qualitative research: interviews and focus groups British Dental Journal 204, 291 - 295.

Goodman, C and Evans Catherine (2010) Focus Groups in: Gerrish, K and Lacey, A (eds) The Research Process in Nursing. Oxford: Wiley-Blackwell.

Halley, G.C (2012) Getting children home on long term ventilation. Paediatrics and Child Health. 22,12, 541-543

Health and Social Care Board (Northern Ireland) (2013) Discharge pathway for children with very complex health needs. Belfast, HSC Board

Heaton, J., Noyes, J., Sloper, P and Shah, R (2003) Technology-dependent children and family life. Research Works, 2003-2, Social Policy Research Unit, University of York: York.

Hewitt-Taylor, J. (2011) Working with Children who need Long Term Respiratory Support. London:M\&K Publishing

House of Commons Health Select Committee (1997) Health services for children and young people in the community, home and school. Third report. London. The stationary office.

Hynson, J., Aroni, R., Bauld, C. and Sawyer, S.M. (2006) Research with bereaved parents: a question of how not why. Palliative Medicine, 20: 805-811.

Johnson J. In-depth interviewing. In: GubriumJ, HolsteinJ, eds. Handbook of Qualitative Research. Thousand Oaks, California: Sage 2002;103-19

King, N. and Horrocks, C. (2010) Interviews in qualitative research. Sage, London.

Kirk, S., \& Pritchard, E. (2012). An exploration of parents' and young people's perspectives of hospice support. Child: Care, Health and Development, 38(1), 32-40.

Kirk, S., Glendinning, C., \& Callery, P. (2005).

Parent or nurse? The experience of being the parent of a technology-dependent child. Journal of Advanced Nursing, 51(5), 456-464.

Kirk, S and Glendinning, C (2004) Developing services to support parents caring for a technology-dependent child at home. Child: Care, Health and Development. 30,3, 209-218.

Kruger, R. and Casey, M. (2015) Focus groups: a practical guide for applied research $\left(5^{\text {th }}\right.$ ed) Thousand Oaks: Sage. 
Margolan, H, Fraser, J and Lenton, S (2004). Parental experiences of services when their child requires long-term ventilation. Implications for commissioning and providing services. Child: Care, Health \& Development 30(3): 257-64

McCloskey, S and Price, J (2014) 'Getting home': An Evaluation of the impact, outcomes and added value step down care provided in a children's hospice setting offers children, families, health and social care providers and commissioners. AVAILABLE AT -http://www.nihospicecare.com/dloads/getting_home_study.pdf

Murphy, G (2001) The technology-dependent child at home Part 1: In whose best interest? Paediatric Nursing. 13, 7, 14-18

Murphy, N., Christian, B., Caplin, D. and Young, P. (2006) The health of caregivers for children with disabilities: caregiver perspectives. Child: Care, Health and Development, 33(2), 180 -187.

Patton, M.Q. (1990) Qualitative evaluation and research methods. Newbury Park, California, SAGE.

Platt H (1959) The welfare of children in hospital. British Medical Journal; 1:166-69.

Polit, D.F. and Beck, C.T. (2014) Nursing Research: Generating and Assessing Evidence for Nursing Practice. $8^{\text {th }}$ edition. Lippincott Williams \& Wilkins.

Royal College of Nursing (RCN) (2011) Informed consent in health and social care research RCN guidance for nurses. Second edition. London.

Ryan, G. and Bernard, H (2000) Data management and analysis methods In Denzin, N. and Lincoln, Y.(eds) Handbook of qualitative research $\left(2^{\text {nd }}\right.$ ed) California: Sage Publications

Ryan, G and Bernard, H R (2003) Techniques to Identify Themes. Field Methods. $15,1,85-109$

Silverman, D. (2000) Doing Qualitative Research. A practical handbook. London, Sage.

Smith, H. and Hilliard, T.(2010) Organizing home ventilation Pediatrics and Child Health 21: 224-229

Together for Short Lives (2016) Children's Palliative Care Definitions. Available at http://www.togetherforshortlives.org.uk/assets/0000/4089/CPC definitions.pdf

earl, D., Cox T, and Hertzog, J (2006) Hospital Discharge of Respiratory-TechnologyDependent Children: Role of a Dedicated Respiratory Care Discharge Coordinator. Respiratory Care Vol 51 No 7,744-749.

Valentine, G. (1999) Doing household research: interviewing couples together and a part. Area, 31, 1, 67-74. 
Wagner, J., Power, E. and Fox, H. (1987) Technology-dependent children: hospital versus home care. Congress of the United States: Office of Technology Assessment.

Wallis, C., Paton, JY., Beaton, S., Jardine, E. (2011) Children on long-term ventilatory support: 10 years of progress Archives of Diseases in Childhood 96 (11) 998-1002.

Wang KW and Barnard A (2004) Technology-dependent children and their families: a review. Journal of Advanced Nursing. 45(1):36-46.

Whiting, M. (2014). Children with disability and complex health needs: the impact on family life: Nursing Children and Young People 26(3), 26-30

Woodgate, R., Edwards, M., Ripat, J.D., Borton, B. and Rempel, G. (2015) Intense parenting: a qualitative study detailing the experiences of parenting children with complex care needs. BMC pediatrics, 15(1). Available at:

http://link.springer.com/article/10.1186/s12887-015-0514-5 [Last accessed: 12.02.2017]. 